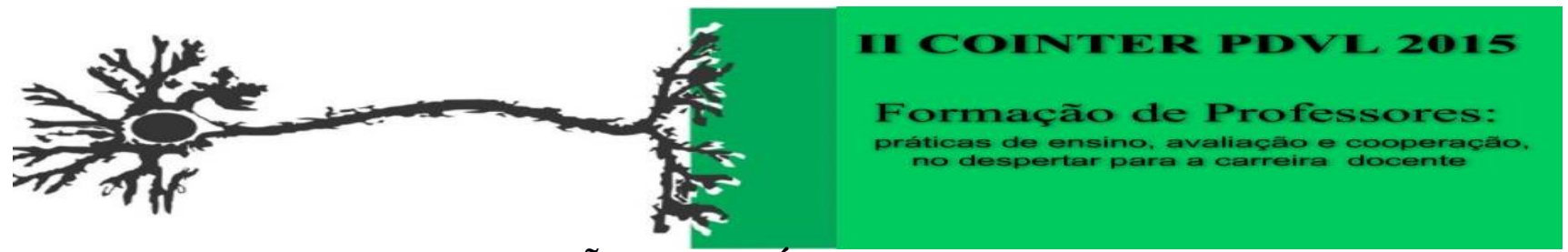

\title{
USO DE REPRESENTAÇÕES IMAGÉTICAS DE PAISAGENS SONORAS EM ATIVIDADES DE ENSINO DE CIÊNCIAS E ACÚSTICA NO ENSINO MÉDIO
}

\author{
Apresentação: Comunicação Oral \\ Jerffeson Daniel Barbosa ${ }^{1}$; Rubens Antonio da $\mathrm{Silva}^{2}$, William Pacheco dos Santos ${ }^{3}$, Francisco Nairon \\ Monteiro Júnior ${ }^{4}$
}

\begin{abstract}
Resumo
O problema da poluição sonora e o pouco caso que o ensino de ciências demonstra com os estudos relacionados a acústica reflete uma falta de consciências auditivas, em que não estamos atentos às paisagens sonoras nas quais estamos inseridos, não temos consciência de seus problemas, não conseguimos identificá-los e resolvê-los. As questões acerca dos estudos de paisagem estão ligados às ciências (física, biologia), às artes (música) e a relação com o ambiente e a sociedade. Assim, para um estudo completo é necessário entender todas essas dimenões. Assim, a física dá a capacidade de entender como o som acontece e suas propriedades e isto é extremamente importante para conseguirmos nos conscientizarmos e sabermos como devemos agir, o que podemos fazer para melhorar o ambiente acústico no qual vivemos. Neste trabalho, usamos representações imagéticas de adolescente do terceiro ano do ensino médio de uma escola pública de Igarassu-PE em atividades de educação sonora, baseadas nas atividades propostas pelo educador musical canadense R. Murray Schafer, na busca da construção de consciências sonoras, na busca por ouvidos pensantes, baseados nos conceitos científicos, para que possamos viver num mundo melhor. Estas representações imagéticas revelaram aspectos importantes sobre como os estudantes veem o mundo e como relacionam o que apredem na escola com as suas vidas cotidianas, indicando que uma análise destes desenhos pode ser uma ferramenta de auxílio para o planejamento dos programas de ensino em ciências e na abordagem a ser feita para a educação sonora e a construção das consciências auditvas e preocupação com o ambiente acústico dentro do currículo das ciências.
\end{abstract}

Palavras-Chave: Acústica, Paisagens sonoras, representações imagéticas, consciências auditivas.

\section{Introdução}

O ensino da física nas escolas de ensino médio tem sido descontextualizado e instrumental, se preocupando apenas em programar o estudante para resolver exercícios matemáticos e não levando em conta suas experiências diárias, desprezando a relação entre os conceitos ensinados e o mundo no qual o estudante está inserido, suas percepções, suas expectativas, etc. As consequências deste ensino instrumental são diversas, desde a incapacidade do estudante de associar o que acontece em seu dia-a-dia e os conceitos científicos, ou seja, não incorporam o que aprendem em

1 Graduando da Licenciatura Plena em Física, Universidade Federal Rural de Pernambuco, jerffesondaniel@hotmail.com

2 Graduando da Licenciatura Plena em Física, Universidade Federal Rural de Pernambuco, rubens.2006@hotmail.com

3 Mestrando do Programa de Pós-graduação em Ensino de Ciências, Universidade Federal Rural de Pernambuco, pachecosantos84@yahoo.com.br

4 Professor do Departamento de Educação, Universidade Federal Rural de Pernambuco, fnmj47@gmail.com 
seus discursos, até um afastamento e a idealização da ciência como algo distante, incompreensível e inatingível.

Em particular, os conceitos relacionados à acústica não têm sido bem explorados no currículo de física no ensino médio. Inserida nos estudos da ondulatória, a acústica ganha pouco destaque e mais uma vez não leva em conta as percepções dos estudantes. Este tópico poderia ser amplamente investigado numa perspectiva interdisciplinar se considerássemos as experiências sonoras e musicais que as pessoas têm e trazem para a sala de aula, ou seja, se abríssemos espaço para o mundo da cultura nas aulas de ciências. Esta desvalorização da acústica nos estudos de física está também nos livros didáticos.

No que tange aos estudos de paisagens sonoras, protagonizados pelo educador canadense Raymond Murray Schafer (2001, 2003), são poucos os trabalhos em ensino de física que se utilizam de tal referencial na busca de estratégias de ensino voltadas para a compreensão dos problemas que envolvem os ambientes acústicos e as suas superações. Nesta perspectiva, a educação científica poderia constituir-se numa aliada importante na formação de consciências auditivas capazes de entender e atuar na melhoria dos ambientes acústicos em que vivemos, agregando valor ao discurso, na medida em que permite a análise dimensional dos atributos relativos à acústica.

Alinhados com essa necessidade de agregar à educação científica essa formação de consciências auditivas, realizamos, na presente pesquisa, um estudo das representações produzidas por estudantes de ensino fundamental e médio de paisagens sonoras no intuito de compreendermos suas percepções por meio de uma pesquisa participante. Impulsionados pela busca de possibilidades para um ensino de física capaz de formar consciências auditivas, expressamos nossa inquietação da seguinte forma: Como as representações imagéticas construídas a partir de experiências auditivas dos estudantes podem revelar traços da forma como entendem estas experiências, tanto do ponto de vista conceitual quanto emocional? Que estratégias de continuidade podem ser pensadas a partir de tais representações em direção à articulação entre ciência e ecologia sonora na formação de consciências auditivas? Estas representações imagéticas nos mostraram alguns fatos sobre a relação dos estudantes com a música, com a ciência, suas percepções das paisagens sonoras, dentre outras coisas. Muitos dos aspectos revelados em tais representações dificilmente poderiam ser expressos pela linguagem escrita ou verbal o que denota a potencialidade desta ferramenta no entendimento da ecologia sonora, na relação do homem com o meio.

Neste cenário, desenvolvemos em duas turmas do quinto ano do ensino fundamental e duas turmas do terceiro ano do ensino médio, a análise de representações, feitas por meio de desenhos, 
de sons e músicas postas à audição dos estudantes de duas escolas: uma escola da rede privada de Recife, PE e uma escola da rede pública de Igarassu, PE. O percurso trilhado por nós deu visibilidade ao potencial de tais representações imagéticas como objeto de estudo dos elementos que compõem o pensamento dos alunos, mostrando conexões não só com o mundo que os cerca e com o que podem ver, mas também com coisas abstratas, como sentimentos. Além disso, revelaram uma associação entre música lenta e morte ou tristeza, além da liberdade que tal estratégia promoveu na construção de histórias para representar as experiências vivenciadas.

\section{Fundamentação Teórica}

Temos habitado um mundo com novos sons. As novas tecnologias propiciaram uma ampliação na faixa de frequência dos sons produzidos, que se limitavam, na Renascença, mais ou menos, à faixa de frequência da voz humana e que vai atualmente dos 20 aos 20 mil Hertz. "Hoje o mundo sofre de uma superpopulação de sons. Há tanta informação acústica que pouco dela pode emergir com clareza. [...] e já não é possível saber o que deve ser ouvido." (SCHAFER, 2001, p. 107). Esse número exacerbado de sons traz consequências negativas: estamos nos acostumando com volumes cada vez mais intensos, estabelecendo ali o "zero" e perdendo a capacidade de perceber sons mais suaves. Schafer (2012, p. 68) define ruído como o som indesejável, o som que interfere. Assim, um ruído pode ser o ranger de uma porta ou o som de um violino, se este for tocado em momento inapropriado. "Para o homem sensível aos sons, o mundo está cheio de ruídos" (SCHAFER, 2003, p. 69).

Historicamente a paisagem sonora, que é um som ou um conjunto de sons que formam um ambiente, mudou e têm constantemente mudado. Um salto na quantidade de sons ocorreu com as Revoluções Industrial e Elétrica. Uma infinidade de ruídos passou a fazer parte do cotidiano das cidades e fomos ficando cada vez mais acostumados com isso, chegando ao ponto de não mais percebermos diversos sons que nos cercam diariamente. Os meios de comunicação também têm um papel importante nesse processo. Atualmente somos uma sociedade muito mais visual, atraída pelo olhar, do que sonora. Se no passado todas as formas de comunicação eram basicamente sonoras, hoje o apelo visual é maior.

Com este aumento indiscriminado da quantidade de ruído, a poluição sonora tem se tornado um problema cada vez maior. "Pode-se dizer que em todo o mundo a paisagem sonora atingiu o ápice da vulgaridade em nosso tempo, e muitos especialistas têm predito a surdez universal como a última consequência desse fenômeno.” (SCHAFER, 2001, p. 17). 
Os sons nos afetam mesmo que não percebamos. Certos sons podem incomodar e nos fazer mal, mesmo que não tenhamos consciência disso. "Mesmo sem se dar conta de que um determinando som o incomoda, o corpo reage e essas reações são as mais variadas: elevação da pressão arterial, aumento do estresse, cansaço, impaciência, indisposição para o diálogo, insônia, ou mesmo, surdez." (FONTERRADA, 2011). É difícil conseguir evitar este som indesejado. Não somos possuidores de pálpebras auditivas, muito embora possamos bloquear psicologicamente a audição dos sons em nossa mente. Contudo, segundo Fonterrada (2004, p. 44) ao fazer isso, “[...] é impossível ao indivíduo selecionar os sons desejados dos indesejados, de modo que tais 'pálpebras psicológicos' bloqueiam a atenção para todos os sons do ambiente, sem discriminação". Como afirma, podemos fechar os olhos, caso uma imagem nos desagrade, podemos deixar de tocar, caso uma textura nos aborreça. O que podemos fazer para identificar e eliminar os sons que nos prejudicam? Há também os sons que nos são agradáveis, que são prazerosos e trazem boas sensações. Como estimular esses sons em meio a, muitas vezes, diversos sons desagradáveis que somos obrigados, por motivo de força maior, a ouvir?

Essa poluição sonora ocorre por que as pessoas não ouvem cuidadosamente e a solução não está simplesmente na diminuição do nível de ruído, mas pensando em quais devemos preservar e multiplicar, tomando assim consciência de quais sons são prejudiciais e devem portanto serem eliminados. Para isso é necessária a construção de uma consciência auditiva, é preciso aprender a pensar auditivamente. Estar atento à paisagem sonora que nos cerca, conseguir refletir sobre ela, saber quais são e como se caracterizam aqueles sons é importante para assegurarmos o bem estar de todos. Somos, assim, corresponsáveis pela qualidade dos ambientes acústicos em que vivemos.

Esta construção está ligada a uma alfabetização científica, onde a ciência ensinada aos alunos tem o objetivo de lhes ser útil na sua formação como cidadãos, fazendo com que eles possam compreender o mundo em que vivem e tomar decisões que afetem suas vidas. A preocupação atual com as questões ambientais, que deve estar integrada ao estudo das ciências, também passa pelas questões sonoras, uma vez que afeta diretamente o bem estar das pessoas, assim como tipos diversos de poluição.

A Física ao tratar da Acústica está voltada para como o som acontece, em explicar o fenômeno. Mas as consequências do fenômeno passam por diversas áreas de estudo e entender o fenômeno também se mostra importante. Porém, é necessário que isto esteja intimamente ligado a vida cotidiana e que possa realmente modificar o estudante e fazer com que, a partir dali, ele consiga incorporar o aprendizado científico ao seu discurso e suas práticas diárias.

Quando um estudante chega à aula de ciências, ele carrega consigo conceitos formados em suas experiências cotidianas, em que já têm explicações e nomenclaturas bem fixas. Assim, 
geralmente o estudante esquece o que aprendeu nas aulas de ciências logo após fazer uma prova sobre o assunto visto e volta às suas antigas concepções. Ou seja, não se está realmente construindo uma consciência científica e não se está conseguindo substituir os conceitos e explicações que já trazem consigo, que são suficientemente fortes para resistir, e não serem abandonados por conceitos científicos. "Muitos desses conceitos e explicações estão permeados por sua experiência corporal mais direta; por exemplo, a ideia de que os objetos têm velocidade, [...]" (DELIZOICOV, et al, 2011, p. 131). Assim, a experiência que já, por exemplo, têm com sons e músicas e as nomenclaturas populares que utilizam se sobrepõem aos conceitos obscuros, longes da realidade, difíceis de compreender e repletos de nomes complexos oferecidos pela ciência. Dessa forma, a ciência não está servindo ao aluno, não está o modificando, não está sendo importante na sua formação enquanto cidadão.

Quando os estudantes chegam à escola, trazem consigo um conjunto de ideias e explicações para fenômenos do cotidiano, muitos dos quais são objeto de estudo das ciências e, em particular, da física. Segundo Driver (DRIVER et al, 1985), estas concepções, que integram esquemas de raciocínio, estão fortemente enraizadas e são altamente resistentes à mudança, podendo persistir durante a vida inteira de uma pessoa, apesar da instrução. Tais concepções estariam presentes em esquemas explicativos que os alunos constroem para muitos dos desafios propostos por professores, tais como as representações imagéticas construídas pelos alunos durante nossa pesquisa.

Durante o desenvolvimento escolar, os estudantes são estimulados a se expressarem utilizando muito mais uma linguagem verbal do que visual. Em contrapartida, são bombardeados por imagens nos meios de comunicação, publicidade, etc., que tem por objetivo chamar sua atenção ou despertar algum sentimento, mesmo que inconscientemente. "Podemos entender uma imagem, a partir do ponto de vista do criador, como uma representação ou interpretação de algo que não está presente e que é capaz de gerar uma série de evocações e sensações no observador" (PRALON, 2010).

Assim, a representação da música, de sons e de paisagens sonoras através de imagens pode revelar muito das interpretações dos estudantes acerca destes e de conceitos científicos ligados à acústica. Uma vez que nossa sociedade se tornou mais visual que sonora e ignora a quantidade e importância dos sons e ruídos a sua volta, fazer com que estudantes representem sons através de desenhos leva-os primeiramente a pensar sobre o que ouvem.

Não apenas relacionado a educação sonora aos conceitos de paisagem sonora, as imagens podem revelar entendimento de conceitos científicos gerais. Além disso, imagens são constantemente utilizadas no ensino de ciências (esquemas, gráficos, fotos) sem que os significados 
estejam bem claros aos estudantes. Suas concepções e dificuldades podem não conseguir ser explicitadas em palavras ou perguntas, mas podem ser reveladas por seus desenhos.

\section{Metodologia}

Nesta investigação em educação, o estudo é tratado sob uma concepção de que a pesquisa deva ser participativa e que contribua para o desenvolvimento dos professores, como afirma Tripp (2005): “A pesquisa-ação educacional é principalmente uma estratégia para o desenvolvimento de professores e pesquisadores de modo que eles possam utilizar suas pesquisas para aprimorar seu ensino e, em decorrência, o aprendizado de seus alunos". A pesquisa-ação busca realizar a pesquisa em meio à prática, onde a pesquisa é feita por meio de uma intervenção. Neste contexto, o pesquisador, ou no caso o pesquisador-professor, exerce influência sobre a pesquisa e busca construir conhecimentos junto com os participantes da pesquisa.

A pesquisa participante em educação contribui na prática docente do pesquisador, uma vez que partindo de suas próprias inquietações, atua enquanto pesquisa e contribui para alguma mudança almejada. "[...] este tipo de pesquisa constitui um meio de desenvolvimento profissional de "dentro para fora", pois parte das preocupações e interesses das pessoas envolvidas na prática, envolvendo-as em seu próprio desenvolvimento profissional" (ENGEL, 2000, apud NUNAN, 1993, p. 41).

Além disso, a atividade da pesquisa-ação garante um retorno para os participantes da pesquisa, neste caso os alunos: enquanto noutras modalidades, o pesquisador simplesmente colhe os dados que lhe são interessantes sem interferir e sem dar nenhum retorno aos participantes, a pesquisa-ação dá uma contribuição aos estudantes. A mudança acontece durante a pesquisa e faz parte deste processo, provocada pela atuação do pesquisador-professor.

A pesquisa-ação ainda permite ao pesquisador-professor que faça uma análise não apenas da atividade que está a desenvolver, mas também de sua prática, de sua ação enquanto professor e pesquisador. Isto permite que ao longo da pesquisa ele busque ajustar, aperfeiçoar sua atuação e busque uma medida ideal entre o dar e o receber, entre o que pode extrair daquela ação e o que pode oferecer em retorno, o quanto pode modificar, o quanto pode contribuir para uma melhoria, seja de que origem for, na comunidade envolvida na investigação.

As atividades para esta investigação foram realizadas com turmas de ensino médio: duas turmas de $3^{\circ}$ ano de uma escola pública de Igarassu-PE. Participaram da atividade 35 estudantes do $3^{\circ}$ ano "A" e 19 estudantes do $3^{\circ}$ ano "B" da escola pública, tendo sido realizado um encontro para a realização de tais atividades.

A atividade consistiu em executar alguns sons e músicas para que os alunos fizessem 
desenhos que representassem o que ouviam, acompanhados de explicações escritas sobre o significado dos desenhos que fizeram, seguidos de conversas e discussões. Ao final do primeiro encontro todos os desenhos foram recolhidos e posteriormente analisados brevemente em busca de padrões e similaridades e desenhos se explicações ou que não estavam tão claros. No segundo encontro houve uma conversa com os alunos sobre seus desenhos, sobre o que significavam e sobre o porquê de terem feitos tais desenhos além de terem sido pedidas explicações sobre os desenhos que não apresentavam clareza ou precisavam de alguma explanação.

Os sons e músicas postas à escuta dos estudantes foram:

i. Som de bolhas;

ii. A música Fireworks de Nicholas Hooper, composta para o filme Harry Potter and the Order of the Phoenix (2007);

iii. A música Time de Hans Zimmer, composta para o filme Inception (2010);

iv. A música Yesterday da banda The Beatles, em uma gravação em versão acústica feita por Savannah Outen e Snuffy Walden, voz e violão, respectivamente.

Tais atividades buscavam perceber como os estudantes representariam as músicas, o que tais representações poderiam revelar sobre suas formações, sobre o ambiente que os cercam, suas experiências, sua bagagem cultural, etc., oferecendo uma contextualização sobre o alunado. A análise desses dados tenta desvendar como o conhecimento desses fatos pode ajudar na prática docente, na preparação e abordagem do professor. "Entender o universo simbólico em que o aluno está inserido, qual a sua cultura primeira, qual sua tradição cultural étnica e religiosa, a que meios de comunicação social tem acesso, a que grupos pertence, pode facilitar o aprendizado das Ciências Naturais" (DELIZOICOV et al, 2011, p. 136). Objetivando o desenvolvimento de uma consciência auditiva, incentivando os estudantes a pensar auditivamente, as atividades, inspiradas nos estudos de R. Murray Schafer, se inserem na busca por uma alfabetização científica, em que se almeja construir uma consciência científica, ensinando em Ciências o que vai ser útil na vida dos cidadãos de maneira que estejam aptas a entender o mundo em que vivem e as tecnologias que o compõe, e possam tomar decisões em que seja necessário entender, mesmo que minimamente, a ciência que possa estar envolvida.

\section{Resultados e Discussão}

$\mathrm{O}$ primeiro som posto à escuta dos estudantes do $3^{\circ}$ ano do ensino médio de uma escola pública foi o som de bolhas. Os resultados estão apresentados na Tabela 4 abaixo. 


\begin{tabular}{|c|c|}
\hline Categorias & Percentual (\%) \\
\hline Bolinhas (sem contexto/explicação) & 32 \\
\hline Panela fervendo & 32 \\
\hline Mar/peixes & 12 \\
\hline Natação & 6 \\
\hline Canudo & 6 \\
\hline Copo com água & 2 \\
\hline Refrigerante & 2 \\
\hline Torneira & 2 \\
\hline Gotas de chuva & 2 \\
\hline Bexiga & 2 \\
\hline Desenho abstrato & 2 \\
\hline
\end{tabular}

Percebemos primeiramente aqui que um grande percentual de estudantes que desenharam simplesmente bolinhas para as bolhas, sem criar um contexto para isso. Isto pode indicar sua maior capacidade de abstração e menor necessidade de ligar a coisas palpáveis, do mundo que as cercam, maior objetividade ou uma maior displicência, menor interesse. Houve também um bom de percentual de desenhos de panelas fervendo, que denota uma aproximação com a ciência ou uma incorporação de conceitos científicos e relação com o dia-a-dia. A falta de contexto é fruto da crescente abstração imposta pela instrumentalização a qual o ensino de ciências está baseado, em que se importa mais as fórmulas e os métodos de resolução de exercícios de repetição que não se conectam com a realidade. Além disso, à medida que se acostumam com os ruídos diários que os cercam, estão menos sensíveis aos sons que compõem o meio no qual se inserem, acabando por limitar a percepção da paisagem sonora. Também, quando se está na presença de um som muito intenso, este limita a paisagem sonora que se pode experimentar. Assim, por som intenso ou costume aos ruídos, a percepção aos sons que estão à volta se torna mais e mais pobre. Presta-se menos atenção ao que se ouve e isto está claramente refletido nos desenhos, embora os dados apresentados contenham apenas os temas centrais do que se foi desenhado.

Para a segunda e terceira atividades foram postas à escuta as músicas Fireworks de Nicholas Hooper, composta para o filme Harry Potter and the Order of the Phoenix (2007), e Time de Hans Zimmer, composta para o filme Inception (2010). As tabelas 5 e 6 mostram os desenhos feitos a partir de Fireworks e Time, respectivamente.

Tabela 2: Categorias dos desenhos dos alunos do $3^{\circ}$ ano para a música Fireworks. Fonte: Própria

\begin{tabular}{|c|c|}
\hline Categorias & Percentual (\%) \\
\hline Violino & 31 \\
\hline
\end{tabular}




\begin{tabular}{|c|c|}
\hline Orquestra & 31 \\
\hline Guitarra & 12 \\
\hline Violão & 8 \\
\hline Teclado & 4 \\
\hline Notas musicais & 2 \\
\hline Dança & 2 \\
\hline Filme & 2 \\
\hline Meditação & 2 \\
\hline Corrida de cavalos & 2 \\
\hline Tambor & 2 \\
\hline Desenho abstrato & 2 \\
\hline
\end{tabular}

Tabela 1: Categorias dos desenhos dos alunos do $3^{\circ}$ ano para a música Time. Fonte: Própria

\begin{tabular}{|c|c|}
\hline Categorias & Percentual (\%) \\
\hline Balé & 32 \\
\hline Cemitério/Morte & 15 \\
\hline Violino & 13 \\
\hline Tristeza & 5 \\
\hline Paz & 5 \\
\hline Guerra & 5 \\
\hline Desenho abstrato & 5 \\
\hline Vela & 2 \\
\hline Sono & 2 \\
\hline Pôr do sol & 2 \\
\hline Natureza & 2 \\
\hline Crucificação & 2 \\
\hline
\end{tabular}

Os estudantes de ensino médio representaram, em sua maioria, a música Fireworks por meio de desenhos de instrumentos musicais, mostrando a associação direta que fizeram da música com o instrumento (ou entre o objeto e o corpo sonoro). Pelo que pudemos perceber, esta música pouco os estimulou a saírem das representações de instrumentos musicais (os corpos sonoros mais óbvios a serem pensados). As paisagens sonoras representadas por meio de desenhos foram pouco detalhadas. Já com a música Time, mais lenta, a incidência de desenhos de instrumentos musicais caiu. Temas como "balé" e "cemitério/morte" tiveram maior representação. 
A última música apresentada foi Yesterday da banda The Beatles, em uma gravação em versão acústica feita por Savannah Outen e Snuffy Walden, voz e violão, respectivamente. Foi escolhido apresentar esta música aos estudantes do ensino médio não apenas instrumental, como eram as músicas anteriores. A tabela 7 mostra os resultados obtidos.

Tabela 1: Categorias dos desenhos dos alunos do $3^{\circ}$ ano para a música Yesterday. Fonte: Própria

\begin{tabular}{|c|c|}
\hline Categorias & Percentual (\%) \\
\hline Amor/romance & 40 \\
\hline Pessoa cantando & 18 \\
\hline Violão & 13 \\
\hline Fim de relacionamento & 11 \\
\hline Natureza & 4 \\
\hline Cemitério/Morte & 4 \\
\hline Tristeza & 2 \\
\hline Teclado & 2 \\
\hline Dança & 2 \\
\hline Amizade & 2 \\
\hline Desenho abstrato & 2 \\
\hline
\end{tabular}

Esta versão da música despertou nos alunos romantismo, tendo $40 \%$ deles desenhado coisas relacionadas a amor/romance, bem como separação, tendo $11 \%$ dos alunos feito referência a fim de relacionamento. Desenhos que refletiam diretamente o que ouviam, como pessoa cantando e violão, também apareceram em considerável quantidade. Desenhos que representavam Cemitério/Morte e Tristeza foram minoria.

Essas atividades nos mostraram que:

i. Os estudantes dessa faixa etária, após terem tido anos de ensino de ciências baseado muito mais numa instrumentalização que uma alfabetização científica, acabam por não se importarem mais tanto com a ligação com o mundo real, buscam uma objetividade típica de exercícios repetitivos de aplicação de fórmulas com os quais estão acostumados. Há de se considerar também que as atividades foram feitas no espaço da aula de física, dessa forma os alunos poderiam ter feito desenhos que esperavam que mais "agradasse" ou que estivessem "certos" ou que mostrasse alguma inteligência da parte dele, como fazem nas aulas. É como se os estudantes entrassem no modo "aula de ciências exatas" e suas ações fossem moldadas a partir disso. 
ii. Houve indícios nestas atividades de uma incorporação de conceitos científicos misturados a coisas do dia-a-dia, que foram externados em seus desenhos (como panela fervendo para o som de bolhas). Isso se evidencia na atividade analisada a seguir.

\section{Conclusões}

O percurso trilhado por nós revelou diferentes inquietações, muito embora todas apontem para a necessidade de continuidade, na busca de possibilidades para o ensino de acústica capaz de formar consciências a serviço da melhoria dos ambientes acústicos. Tais inquietações estão delineadas abaixo, seguidas de possibilidades de continuidade frutos de suas análises em seus contextos de busca.

i. Nas representações imagéticas dos adolescentes foram encontradas elementos da objetividade científica. Esta objetividade, além da pouca imaginação mostrada nos desenhos, parece denotar como a escola tem influenciado ou moldado seu comportamento, mas não suas concepções, uma vez que se observou pouco entendimento dos conceitos científicos, e um discurso confuso, fruto de um aprendizado desvinculado dos problemas do cotidiano.

ii. A associação entre objetos sonoros e corpos sonoros, foi a mais imediata encontrada por eles para representar suas experiências, como por exemplo, a associação simples entre os sons ouvidos e instrumentos musicais, sempre relacionando com seus cotidianos ou com coisas mais palpáveis, de fácil acesso. A incorporação dos conceitos científicos no movimento de conscientização para a audição passaria pela substituição gradativa de tais corpos sonoros pelas representações científicas dos objetos sonoros.

Um ensino de acústica que não busca, como ponto de partida, as experiências sonoras que as pessoas têm, nem tampouco as interpretações de tais experiências, transpostas em linguagem, mesmo que esta seja simples e fielmente, representações imagéticas infantis, está fadada a um misto quase sempre forjado entre conceitos mal aprendidos e representações que não são mais subjetivas, como as primeiras, nem objetivas como as que a ciência positivista almeja formar nas pessoas. Mais parecem um misto de desespero de quererem se livrar da tarefa do professor. E a audição? Fica pra depois. Depois quando? Quando as pessoas não forem mais capazes de sentir aquilo que ouvem, ensurdecidas pela falta de maturidade de uma sociedade que não se preocupa com a qualidade dos ambientes sonoros? A questão é ambiental, é de bem estar, é importante para a relação em o ser humano e o meio em que vivemos e da vida em sociedade. Assim como outros problemas ambientais, a poluição sonora é Temos que aprender a ouvir com o mesmo interesse e cuidado com 
os quais vemos. Deve ser por meio da educação científica que esta preocupação com os ambientes sonoros deve ser atingida. Devemos aprender a ouvir melhor para viver melhor.

\section{Referências}

DELIZOICOV, D. et al. Ensino de ciências: fundamentos e métodos. 4 ed. São Paulo: Cortez, 2011.

DRIVER, R; GUESNE, E; TIBEREGHIEN, A. Children's Ideas in Science. Milton Keynes: Open University Press, 1985.

FONTERRADA, M. T. O. Música e meio ambiente: ecologia sonora. São Paulo: Irmãos Vitale, 2004.

FONTERRADA, M. T. O; CARNELÓS, M. O mundo soa. Vamos ouvir? Projeto Caminhos Sonoros, Mairiporã, 2011.

PACHECO, C. B. O uso de desenhos no estudo da percepção musical: um estudo preliminar com crianças. Música Hodie, Goiânia, v. 7, nº 1, 2007.

PRALON, L.H. Imagens científicas e ensino de ciências: uma experiência docente de construção de representações simbólicas a partir do referente real. In: ENCONTRO NACIONAL DE DIDÁTICA E PRÁTICA DE ENSINO (ENDIPE), 15., 2010, Belo Horizonte.

SCHAFER, R. M. A afinação do mundo. Tradução: Marisa Trench de Oliveira Fonterrada. São Paulo: Editora da UNESP, 2001.

O ouvido pensante. 2 ed. Tradução: Marisa Trench de Oliveira Fonterrada, Magda R. G. da Silva e Marta Pascal. São Paulo: Editora da UNESP, 2003.

Eu nunca ouvi um som. Tradução: Marisa Trench de Oliveira Fonterrada, Magda R. G. da Silva e Marta Pascal. ARTEunesp, São Paulo, n.9, p. 85-90, 1993. 